\title{
FROM BEST INTERESTS TO BETTER INTERESTS? VALUES, UNWISDOM AND OBJECTIVITY IN MENTAL CAPACITY LAW
}

\author{
John CogGON* (iD) AND CAmillia KonG**
}

\begin{abstract}
The Mental Capacity Act 2005 governs personal decisionmaking for adults. It incorporates five overarching principles, including that incapacity may not be inferred merely from a person's unwise decisions and that where a person lacks capacity decisions must be made in her best interests. Through analysis of judicial treatment of unwisdom, best interests, subjectivity and objectivity, considered against parliamentary debates on the Mental Capacity Bill and philosophical critique of ideas of (un)wisdom, we argue that these principles are problematically irreconcilable. The Act's radical under-specificity means, paradoxically, that this comes to be resolved through abstracted values, rather than the centricity of the person herself.
\end{abstract}

KEYworDs: mental capacity, best interests, unwise decisions, objective values, subjective values, personal decision-making.

\section{INTRODUCTION}

The Mental Capacity Act 2005 (MCA) provides the rules and principles in England and Wales that govern and protect personal decision-making for adults regarding their health, welfare and property and affairs. ${ }^{1}$ It was

* Centre for Health, Law and Society, University of Bristol Law School. Address for Correspondence: University of Bristol Law School, 8-10 Berkeley Square, Bristol, BS8 1HH, UK. Email: John. Coggon@bristol.ac.uk. We are grateful to the Arts and Humanities Research Council for its support through the Judging Values and Participation in Mental Capacity Law project (AHRC Grant Reference: AH/R013055/1). Many thanks to our colleagues on the project, Penny Cooper, Michael Dunn, Rebecca Stickler, Victoria Butler-Cole QC and Alex Ruck Keene, for their comments and suggestions in relation to this paper. Thanks also to Suzanne Doyle Guilloud, Sara Fovargue, Stephen Latham, Stephen W. Smith and Cameron Stewart and two anonymous reviewers for their supportive and detailed comments. We are grateful too to colleagues at the 2019 Society of Legal Scholars Annual Conference's Medical Law stream and attendees at a Southampton Law School Centre for Health, Ethics, and Law seminar at which earlier versions of this paper were presented. The views expressed in the paper are those of the authors.

** Institute for Crime and Justice Policy Research, Birkbeck, University of London.

1 The MCA also applies to children aged 16 and 17, for whom legal decision-making capacity does not apply in the same way as for adults. Our focus in this paper is on the law as it relates to adults. 
drafted with an empowering ethos, enumerating five overarching, "cardinal"2 principles in section 1:

\section{The Principles}

(1) The following principles apply for the purposes of this Act.

(2) A person must be assumed to have capacity unless it is established that he lacks capacity.

(3) A person is not to be treated as unable to make a decision unless all practicable steps to help him to do so have been taken without success.

(4) A person is not to be treated as unable to make a decision merely because he makes an unwise decision.

(5) An act done, or decision made, under this Act for or on behalf of a person who lacks capacity must be done, or made, in his best interests.

(6) Before the act is done, or the decision is made, regard must be had to whether the purpose for which it is needed can be as effectively achieved in a way that is less restrictive of the person's rights and freedom of action.

The MCA affirms that adults are assumed to have capacity to make decisions for themselves. This assumption may only be displaced if, after all practicable steps to allow a person to make a decision have been exhausted, both "functional" and "diagnostic" criteria to determine incapacity are met. First, a person must be shown to be unable to understand, retain, or weigh or use relevant information, or to communicate her decision; ${ }^{3}$ second, this must be "because of an impairment of, or a disturbance in the functioning of, the mind or brain". ${ }^{4}$ Following a finding of incapacity, a decision maker (referred to in the statute as "D") then makes a decision for the person (who in these circumstances is referred to as "P") which must be in P's best interests.

This article focuses on the MCA's third and fourth principles, enshrined respectively in sections 1(4) and 1(5). The third principle, on which the statute provides no further explanation, guards against incapacity determinations being made merely on the basis of a person's decision being "unwise". The Act's fourth principle, which does receive further elaboration - in section 4 - provides a best interests standard as the basis of decisions made for P. Section 4 maintains the ethos of P-centricity within best interests decision-making: for example, by providing for P's optimal participation and including P's wishes, feelings, beliefs and values as relevant factors in the decision. ${ }^{5}$

${ }^{2}$ King's College Hospital NHS Foundation Trust $v$ C and $V$ [2015] EWCOP 80, at [25]-[39] (MacDonald J.); Re D (Incapacitated Person) (Representatives and Advocates: Duties and Powers) [2016] EWCOP 49, at [82] (Baker J.)

3 Mental Capacity Act (MCA) 2005, s. 3(1).

${ }^{4}$ Ibid., s. 2(1). The criteria as listed here are in the opposite order to that given in the statute, in accordance with the logical priority of undertaking the section 3 test for capacity first, and only then and if the section 3 test suggests incapacity, section 2: PC v City of York Council [2013] EWCA Civ 478, [2014] 2 W.L.R. 1, at [58]-[59] (Macfarlane L.J.).

${ }^{5}$ MCA, ss. 4(4), 4(6) 
Given its reach and ambitions, and the contextualism required for their achievement, the MCA was understandably developed as framework legislation with principles at its core. As it neared its final stages of progression through Parliament, Baroness Barker, who had been a member of a Joint Committee of the House of Lords and House of Commons that provided pre-legislative scrutiny to the Bill, ${ }^{6}$ explained why "we have this Bill of principle", 7 stating:

Of necessity, this is a framework Bill. We on this side of the House do not normally like framework Bills, but this is an exception - because it should be. Much is left to regulations, guidance and codes of practice. ... This is right because in the legislation we seek to determine what will happen to millions of people whose circumstances are different. That is why it is important that we have this Bill with those principles at the very heart of it. ${ }^{8}$

Given the MCA's emphasis on the particular person and her circumstances, a lack of specificity within the legislation is thus overtly rationalised: a foundation on particular principles may be considered a desirable - even a necessary - legislative method to overcome challenges of bespoke application. However, it is problematic if the principled framework is on its own terms incoherent, or if the norms that arise through its subsequent jurisprudential developments lead to incoherence. This article argues that sections 1 (4) and 1(5) cause such problems. Specifically, it is argued that the inclusion of unwisdom as a defining statutory principle renders problematic the function and application of the third and fourth principles, whereby the concept of "unwise" is used simultaneously as a shield concept to protect a person's autonomy and as a negative counterpoint to distinguish best interests decision-making from a person's decision-making on her own behalf.

It is important to understand how the unwise decisions provision renders the MCA's principled framing unstable. The wealth of case law since the inception of the legislation enables us to undertake a critical assessment of whether the statute and its judicial application have properly met purported objectives of promoting P-centricity and P-specificity. Despite the P-centric interpretation of best interests in the Supreme Court's judgment in Aintree University Hospital NHS Foundation Trust $v$ James, ${ }^{9}$ the House of Lords Select Committee Report on the MCA in 2014 had observed failures in implementing the empowering ethos of the Act, attributable partly to " $[\mathrm{t}]$ he concept of unwise decision-making fac[ing] institutional obstruction due to prevailing cultures of risk-aversion and

\footnotetext{
${ }^{6}$ Report of the Joint Committee on the Draft Mental Incapacity Bill, vol. 1 (London 2003).

${ }^{7}$ HL Deb. vol. 668 col. 22 (10 January 2005).

${ }^{8}$ Ibid. See also the explicit endorsement of Baroness Ashton, then parliamentary under-secretary of state at the Department of Constitutional Affairs, at HL Deb. vol. 668 col. 98 (10 January 2005).

9 [2013] UKSC 67, [2014] A.C. 591.
} 
paternalism" and leading more generally to best interests decision-making "often not [being] undertaken in the way set out in the Act: the wishes, thought and feelings of $\mathrm{P}$ are not routinely prioritised". ${ }^{10}$ Whilst the Select Committee identified institutional failures in enacting the objectives of the MCA, what is less recognised is how incoherence at the level of the statute's principled foundation may obstruct the implementation of P-centric decision-making. In theory, specific provisions in section 4 would appear to shore up the importance of P-centricity, but these provisions are sometimes treated as supplementary obligations, ${ }^{11}$ generating the need to explore the more fundamental cause for person-centredness to go by the wayside in best interests decision-making through a critical examination of the MCA's principled framing in section 1. Contradictory interpretations of section 1 principles lay bare an unstable conceptual grounding and articulation of P-centricity, such that this statutory objective is in danger of inevitably becoming meaningless in both substantive content and practical application.

This article therefore has a critical, diagnostic purpose - to illuminate two possible reasons for the incoherence at the principled foundation of the MCA. The first is contextual: an account of parliamentary debates on protecting unwise decisions in Section II of this paper helps highlight a radical distinction between the Government's interpretation of (what was to become) section 1(4)'s implications, as contrasted with subsequent judicial analysis of it. As Section III shows, judicial interpretation has led to a fundamental irreconcilability between sections 1(4) and 1(5), pitting the unwise decision principle and best interests standard in contradistinction with one another. Particular problems arise because of inconsistencies regarding the place of unwisdom within best interests; not least that best interests assessments - rooted in concepts and cognates of wisdom - can be seen to impinge on determinations of and around (in)capacity.

The second reason is conceptual, in so far as the idiosyncratic operationalisation of "unwise" in the MCA departs from a more intuitive, normative concept of wisdom. Our argument shows how the phrase "unwise decision" in the statute denotes an unusual meaning. It was intended to act as a guard against presumptions of incapacity; effectively to permit and protect individual eccentricity and autonomy. The phrase, however, works simultaneously to preserve the validity of wisdom as an ideal against which best interests decisions are evaluated. Appeals to wise/unwise presuppose broad agreement on the normative desirability of wisdom in decisionmaking, or at least recognise the force of normative intuitions associated with both ordinary and philosophical understandings of the term. Where

${ }^{10}$ HL Select Committee on the Mental Capacity Act 2005, Mental Capacity Act 2005: Post-Legislative Scrutiny (London 2014), ch. 3, at [104].

${ }^{11}$ See e.g. University Hospitals Bristol NHS Foundation Trust v ED [2020] EWCOP 18. 
unwise decisions are excluded from decisions made for $\mathrm{P}$, there is a tendency to look to distinct duties towards $\mathrm{P}$ and to relate the rationalisations to values that are objective rather than subjective. Section IV critically explains judicial approaches to the objective/subjective distinction which do not straightforwardly track parliamentary intentions to protect $\mathrm{P}$ from D's subjective values, aiming rather - or in addition - to deny the weight of P's own subjective values. We argue that the underlying theoretical roots of judicial approaches can be traced back to a more normative Aristotelian conception of wisdom that fundamentally conflicts with the liberal and subjectivist framing in section 1(4). By implication, wisdom/unwisdom come to be understood in ways that are either too "thick" or demanding, or too "thin" or normatively impoverished. We conclude that a focus on (un)wisdom is conceptually unstable in itself, making it problematic when set as a reference against which other principles may be assessed (especially protection of best interests) and the overall person-centred aims of the MCA. Though we do not provide a resolution to the instability in the statute's principles, our analysis is vital to spur on much-needed internal as opposed to external critical reflection, ${ }^{12}$ where examination of the MCA on its own terms reveals a significant divergence between the statute's principled bases and its objectives of promoting P-centricity and P-specificity in best interests decision-making. ${ }^{13}$

${ }^{12}$ Few works have critically assessed the principles of the $M C A$ against the intent of the legislation. Prominent examples of external critiques assess the MCA from particular interpretations of the United Nations Convention on the Rights of Persons with Disabilities (CRPD), particularly the CRPD Committee's "General Comment No. 1 (2014) - Article 12: Equal Recognition Before the Law" (CRPD/C/GC/1, 2014). See also P. Bartlett, "At the Interface Between Paradigms: English Mental Capacity Law and the CRPD" (2020) 11 Frontiers in Psychiatry 881; N. Crowther and L. Sayce OBE, "Was Ratification of the CRPD the High Watermark for United Kingdom Disability Rights? Ten Years of Monitoring Implementation of the CRPD" in E.J. Kakoullis and K. Johnson (eds.), Recognising Human Rights in Different Cultural Contexts (Singapore 2020), 297-332. For critiques from an internal, albeit more conceptual, perspective, see C. Kong, Mental Capacity in Relationship: Decision-making, Dialogue, and Autonomy (Cambridge 2017); P. Skowron, "The Relationship Between Autonomy and Adult Mental Capacity in the Law of England and Wales" (2019) 27 Med.L.R. 32. Recent work has also provided a retrospective perspective of how the MCA is functioning around disputes of capacity: see A. Ruck Keene et al., "Taking Capacity Seriously? Ten Years of Mental Capacity Disputes before England's Court of Protection" (2019) 62 International Journal of Law and Psychiatry 56.

13 Best interests decision-making has also been interpreted and evaluated against the CRPD emphasis on supported decision-making: see R. Harding and E. Taşcioğlu, "Supported Decision-making from Theory to Practice: Implementing the Right to Enjoy Legal Capacity" (2018) 2 Societies 25; L. Series, "Relationships, Autonomy and Legal Capacity: Mental Capacity and Support Paradigms" (2015) 40 International Journal of Law and Psychiatry 80; G. Richardson, "Mental Disabilities and the Law: From Substitute to Supported Decision-making?" (2012) 65 Current Legal Problems 333; R. Barton-Hanson, "Reforming Best Interests: The Road Towards Supported Decision-making' (2018) 40 Journal of Social Welfare and Family Law 277. Important as these discussions are, we do not make the claim that the P-centric objective of the MCA is necessarily coextensive with supported decision-making; indeed, the concept of unwise/wise putatively falls away if one presumes the primacy of enacting P's subjective wishes through a supported decision-making framework. 


\section{Rationalising and Framing UNWISE Decision-Making Rights AND Best InTERests in the Mental Capacity Bill}

Parliamentary debates on the unwise decisions and best interests provisions give a crucial backdrop to understanding how these concepts have informed and shaped mental capacity jurisprudence. The final stages of the Mental Capacity Bill's passage through Parliament are especially instructive. They took place against the context of the Government pushing to pass the legislation prior to Parliament's dissolution before the general election of May 2005. However, the overall law reform efforts leading up to the enactment of the MCA may be seen as a 15-year long process, including a Law Commission inquiry, Government consultation, policy statement and pre-legislative scrutiny of the 2003 Draft Mental Incapacity Bill by the Joint Committee referred to above. ${ }^{14}$

The debates taken as a whole tended towards a preponderant focus on euthanasia; notwithstanding that the Bill would have a far broader reach and application than end-of-life decision-making. As stated by Lord Falconer, then secretary of state for constitutional affairs and Lord Chancellor: "The Bill seeks to do much more than deal with the issue of decisions concerning the giving of life-sustaining treatment to adults who lack capacity. ... I very much hope that the other issues the Bill covers do not get obscured by these issues." 15

Of central relevance to this paper are the characterisations of and rationalisations for distinct ways of conceiving and protecting/disregarding unwise decisions and best interests. Relating to the former, David Lammy M.P., then parliamentary under-secretary of state for constitutional affairs, stated that making an unwise decision is not equivalent to suffering the inability to make a decision: "We have all done things that our family or friends think are unwise. In a sense, the intention is to give people with impaired mental capacity the chance to express their individuality, as everyone else does." 16

The focus is on the protection of a conception of personal autonomy; of rights to make decisions - wise or unwise - without interference. Joan Humble M.P., who had been a member of the Joint Committee on the Draft Mental Incapacity Bill, reiterated Lammy's interpretation in an exchange with Meg Munn M.P.:

My honourable friend and I could make an unwise decision and people could say, "Why did they do that? I don't agree with them." We have to recognise

\footnotetext{
14 The influence of these on the legislation is recounted in P. Letts, "Mental Capacity Act 2005: The Statutory Principles and Best Interests Test" (2005) Journal of Mental Health Law 150. On the unwise decisions provision, Letts concludes, "Some caution may therefore need to be applied in operating this principle in practice", at [154]. This relates especially to concerns raised by Denzil Lush (discussed below), who was Master of the Court of Protection at the time Letts was writing.

${ }^{15}$ HL Deb. vol. 668 col. 13 (10 January 2005). Such points were made in both Houses, e.g. Paul Burstow M.P.: HC Deb. vol. 425 cols. 47-48 (11 October 2004).

${ }^{16}$ HC Deb. vol. 425, cols. 25-26 (11 October 2004).
} 
that the individuals covered by the Bill will also sometimes make unwise decisions. The independent advocacy service might well simply say that, although it might seem unwise to everyone else in the room, Mr. X - or P, in the terminology of the Bill - actually wants to make that decision. We have to allow them to make unwise decisions. ${ }^{17}$

This approach is also evident in the House of Lords, with Baroness Ashton, then parliamentary under-secretary of state at the Department for Constitutional Affairs, noting that: "The question of whether something is unwise is debatable. ... But could a noble Lord who has never made an unwise decision please stand up? It is part and parcel of being autonomous." 18

The Government's rationale for the unwise decisions principle thus emphasises a particular conception of autonomy. Presented as being of fundamental importance, autonomy is interpreted here as a thin value; a person deciding for herself is what matters, rather than the quality of her decisionmaking. This "liberal" interpretation of unwise decisions was challenged in the debates for its express inattention to the substance of the decision itself. Amongst the objections, two warrant explicit mention. First is Lord Brennan's proposed amendment to qualify the unwise decisions principle in the following terms:

but any decision, whether unwise or not, is inapplicable and invalid it if is -

(a) wholly irrational in the opinion of the medical practitioner responsible for the treatment, or any other decision maker including a court;

(b) in all the circumstances against the public interest, namely -

(i) to preserve life;

(ii) to prevent suicide;

(iii) to protect the integrity of the medical and nursing professions; and

(iv) to protect innocent third parties. ${ }^{19}$

This is startling for its aim to disregard protections of thin conceptions of autonomy; allowing for instances where autonomy might be outweighed and introducing "matters which any expression of common sense - any sentiment of the best interests and common good of society - would want in the Bill". ${ }^{20}$ Society "should not be saddled with the consequences of wholly irrational decisions" meaning we should challenge the position that "personal autonomy should apply, even if that autonomy has been expressed wholly irrationally". ${ }^{21}$

\footnotetext{
17 Ibid., col. 74.

18 HL Deb. vol. 668 col. 1180 (25 January 2005).

19 Ibid., cols. 1143-4.

20 Ibid., col. 1144.

21 Ibid., col. 1145.
} 
Lord Brennan's amendment was not passed. Of relevance here is part of Lady Barker's response which emphasised that "perhaps the paramount principle [of the Bill] is that people must be treated as individuals". ${ }^{22}$ Another notable objection to the Bill's protections of unwise decisions came from Lord Christopher, who emphasised the problems of focusing excessively on life and death cases. Drawing from comments made by the then Master of the Court of Protection (CoP), Denzil Lush, ${ }^{23}$ Lord Christopher favoured a pushback against the Government's position. He challenged the Bill's focus on individual decisions, with its consequent blindness to the aggregate effect of successive unwise decisions. Rather than noting the importance of permitting unwise decisions for persons who are deemed to lack capacity, he stressed the idea of "wholly irrational" applying to instances where no incapacity determination has been made in the context of financial decision-making. ${ }^{24}$

Against these (and other) challenges, the prevailing rationale for the final framing of section 1(4) reveals that the phrase "unwise decisions" was intended to defend against setting a higher standard of conduct for persons with disabilities than applies to others: those with impaired capacity should be able to express themselves in ways consistent with a liberal commitment to value pluralism, individuality and subjective free expression. "Unwise" is delinked from standards of objectivity and instead viewed as a constitutive feature of autonomy. The legislative intent behind unwise decisions was clear: to guard against value-laden judgments in capacity assessments that would disqualify the idiosyncratic decision-making of persons with disabilities. ${ }^{25}$

But does this liberal interpretation of unwise decisions likewise apply to the best interests standard? Here the second reading debate in the House of Lords is equally illuminating in its ambiguous appeal to "objectivity" in best interests decision-making. ${ }^{26}$ Objectivity within the context of what became sections 1(5) and 4 of the MCA is predominantly understood as considering all relevant factors (including those that may be independent of P's own views), often evoking a sense of making a decision independent of or impartial to a particular subjective perspective and set of values. Objectivity thus turns on an intellectual and attitudinal orientation towards the decision, which then itself becomes a constitutive feature of the "best" decision. A potential wedge between what is the "better" best interests decision and the unwise viewpoint of $\mathrm{P}$ is the logical consequence: an interpretation that appears consistent, for example, with the explanatory notes to the

\footnotetext{
22 Ibid., col. 1155.

23 See D. Lush, "The Mental Capacity Act and the New Court of Protection" (2005) Journal of Mental Health Law 31.

24 See HL Deb. vol. 668 cols. 1162-3 (25 January 2005).

25 Also Lush, "The Mental Capacity Act and the New Court of Protection", 33.

26 HL Deb. vol. 668 cols. 11-26 (10 January 2005).
} 
MCA, ${ }^{27}$ with Lady Hale's decision in Aintree $v$ James, ${ }^{28}$ and with former Senior Judge Lush's framing, ${ }^{29}$ all discussed in Section III, below. ${ }^{30}$

Yet a reading of the House of Lords' debate reveals a departure from this conventional interpretation. Objectivity is used as a concept that shields and safeguards P from the imposition of D's subjective values. In this alternative, if slightly inchoate interpretation, objectivity forces a conceptual wedge between best interests and the subjective viewpoint of $D$, and not necessarily between best interests and $P$ 's unwise/subjective decisions. ${ }^{31}$ For example, Lord Falconer stated (in a point focused on removing or withholding life-sustaining treatment; the most heated issue within the parliamentary debates on the Bill) that the decision maker "must make an objective assessment" of best interests, which means that the "decision cannot simply be the personal value judgment of the decision-maker" whereby the decision maker wrongfully puts herself in P's position. ${ }^{32}$ Reiterating the importance of P's perspective, Lord Falconer affirmed the P-centric intention of the best interests test so as to "ensur[e] that the person himself is the focus and driver of all decision-makers". ${ }^{33}$

Baroness Ashton echoed this meaning of objectivity as protecting $\mathrm{P}$ against D's subjective views rather than the subjective (and potentially unwise) views of $\mathrm{P}$ herself: "Our determination is to ensure that the best interest clause in the Bill is truly objective and that the decision makers' personal desire plays no part in that." ${ }^{34}$ The intention behind objectivity as a standard in best interests is given within these framings as protecting $P$ against the potential infiltration of a third-party decision maker's subjective views, ensuring that P-centric decisions are enacted.

Tracing the genealogy of the phrase "unwise decisions" and the objectivity standard in parliamentary debates thereby brings into sharp relief a focus on individuality and subjective freedom in legislative intent. In Baroness Ashton's words: "it is important that we enable people to make decisions that we consider to be unwise." 35 Important to note too is that the drafting of section 1(4) does not require unwisdom to be considered at all in approaching best interests: although unwisdom should not be the basis of a determination of incapacity, it does not follow that it may, less still should, be a standard to feature in or be contrasted against best interests

\footnotetext{
27 See "Explanatory Notes: Mental Capacity Act 2005", available at http://www.legislation.gov.uk/ukpga/ 2005/9/notes (last accessed 17 March 2021).

28 [2013] UKSC 67, [2014] A.C. 591.

29 See especially text to note 74 , below.

${ }^{30}$ Consider in the same vein the framing of objective versus subjective in, e.g., M. Donnelly, "Best Interests, Patient Participation and the Mental Capacity Act 2005" (2009) 17 Med.L.R. 1.

${ }^{31}$ Cf. J. Coggon, "Mental Capacity Law, Autonomy, and Best Interests: An Argument for Conceptual and Practical Clarity in the Court of Protection" (2016) 24 Med.L.R. 396.

${ }^{32}$ HL Deb. vol. 668 col. 15 (10 January 2005).

${ }^{33}$ HL Deb. vol. 668 col. 16 (10 January 2005).

${ }^{34}$ HL Deb. vol. 668 col. 99 (10 January 2005).

35 Ibid.
} 
decisions (nor is it mentioned in section 4 where that standard is further explicated). The debates considered here place emphasis on installing mechanisms to protect P's autonomy. As shown in the remainder of this paper, the liberal interpretation of "unwise" within parliamentary debates runs counter to a more normative conception of wisdom that provides a latent backdrop to judicial approaches to MCA cases, leading to clear interpretive tensions and ambiguities regarding the permissibility of unwise decisions in best interests.

\section{Judicial Approaches to Personal Decision-making: Personal} Values and the Dynamic Between "Subjective" versus "ObJective"

\section{A. The Clear Rule for Persons with Capacity and the Less Clear Rule for Those Who Are Deemed to Lack Capacity}

The parliamentary debates considered above show clear attempts to extend and protect the subjective autonomy of persons with disabilities, particularly in their making idiosyncratic choices. This normative aspiration was expressed through a liberal interpretation of unwise decisions that did not necessarily hinge on drawing a sharp distinction between the person with or without capacity. Yet the practice and interpretation of the MCA have followed a more ambiguous line. The main trend has been towards ascribing the right to make autonomous (including unwise) decisions as correlative to a duty of non-interference towards the capacitous individual. However, the best interests obligations to those lacking capacity are taken to demand greater scrutiny of the substance and weight of P's subjective values.

To explain this, English mental capacity law can be observed as holding twin, and potentially antagonistic, ${ }^{36}$ aims: promoting autonomy rights and ensuring protection from physical, psychological, emotional and financial harm. In the Supreme Court case of Aintree $v$ James, ${ }^{37}$ Baroness Hale holds:

A person who has the capacity to decide for himself can of course make decisions which are not in his own best interests and no doubt frequently does so. Indeed, the Act provides that a person is not to be treated as unable to make a decision simply because he makes an unwise one: section 1(4). But both at common law and under the Act, those who act or make decisions on behalf of a person who lacks capacity must do so in his best interests: section 1(5). ${ }^{38}$

This is a precise and clear representation of capacity law: interference with a capacitous adult's personal, self-regarding decision is impermissible,

\footnotetext{
${ }^{36}$ Cf. Lush, "The Mental Capacity Act and the New Court of Protection"; M. Dunn and C. Foster, "Autonomy and Welfare as Amici Curiae" (2010) 18 Med.L.R. 86.

${ }^{37}$ [2013] UKSC 67, [2014] A.C. 591.

38 Ibid., at [23].
} 
however unwise, unreasonable, rash or irrational it may be. ${ }^{39}$ A person may be free to divest herself of all her wealth, or harm herself physically, emotionally or psychologically, without rhyme or reason. As Lord Donaldson M.R. states in the landmark refusal of medical intervention case, $R e T^{40}$ :

An adult patient who ... suffers from no mental incapacity has an absolute right to choose whether to consent to medical treatment, to refuse it or to choose one rather than another of the treatments being offered.... This right of choice is not limited to decisions which others might regard as sensible. It exists notwithstanding that the reasons for making the choice are rational, irrational, unknown or even non-existent. ${ }^{41}$

Consistently with Lord Donaldson's dicta, the MCA's explanatory notes state:

[A] person is not to be treated as lacking capacity to make a decision simply because he makes an unwise decision. This means that a person who has the necessary ability to make the decision has the right to make irrational or eccentric decisions that others may not judge to be in his best interests .... Everything done, or decision made, under the Act for a person who lacks capacity must be done in that person's best interests. ${ }^{42}$

Again, the contradistinction between decision-making by persons who have capacity and for persons who lack capacity is apparently clear. The guiding principle of individual autonomy for persons who have capacity may accordingly be represented in crisp terms: ${ }^{43}$ it is up to her what happens. ${ }^{44}$ The exercise of respecting and protecting the capacitous person's autonomy obtains, in principle at least, not in identifying values to motivate a decision, less still in the endorsement of such values. Rather, respecting autonomy within this framing means assuring the conditions for a person to act on her decision howsoever it may be founded. ${ }^{45}$

This "thin" idea of autonomy, which permits for "unwise" decisions, is commonly placed in judicial reasoning as necessarily oppositional to a more substantive and "objective" standard to explain decisions that are made under the best interests standard. McFarlane L.J., for example, in PC $v$ City of York Council, ${ }^{46}$ expresses how protections of unwise

39 Subject to constraints, for example, as found in the Mental Health Act 1983.

40 [1992] Fam 95.

41 Ibid., at 102, emphasis added.

42 See "Explanatory Notes: Mental Capacity Act 2005", at [20].

43 Albeit within the necessary constraints on action provided, for example, by limits on positive claims to public resources, criminal and civil liabilities for harms to others and their interests, and so on: J. Coggon and J. Miola, "Autonomy, Liberty, and Medical Decision-Making" [2011] C.L.J. 523; Coggon, "Mental Capacity Law, Autonomy, and Best Interests".

44 See e.g. MacDonald J. in King's College Hospital $v C$ and V [2015] EWCOP 80, at [97].

45 The claim in this sentence holds in principle, given the combined protection of a person's freedom to make an unwise decision in section 1(4) and the value-empty functional test for (in)capacity in section 3 (1); in practice values do nonetheless feature, particularly in assessments of P's exercise of weighing and balancing information, casting doubt as to whether principle and practice always align.

46 [2013] EWCA Civ 478. 
decisions, with a blindness to their outcomes, reflects an opposition of the principles in sections 1(4) and 1(5):

The individual's decision may be said to be "against the better judgment" of the woman concerned, but the point is that, unless they lack mental capacity to make that judgment, it is against their better judgment. It is a judgment that they are entitled to make. The statute respects their autonomy so to decide and the Court of Protection has no jurisdiction to intervene.

$[T]$ here is a space between an unwise decision and one which an individual does not have the mental capacity to take and ... it is within that space that an individual's autonomy operates. ${ }^{47}$

Lewison L.J. echoes the position: "adult autonomy is such that people are free to make unwise decisions, provided that they have the capacity to decide." ${ }^{48}$ We have a firm distinction, notwithstanding - as noted above that section 4 makes no mention of "unwise" or its logical exclusion.

Strikingly, despite the elaboration in section 4, the best interests standard is by design legislated without the substantive content that is necessary to give it meaning. As the MCA's explanatory notes state: "Given the wide range of acts, decisions and circumstances that the Act will cover, the notion of 'best interests' is not defined in the Act. Rather, [s. 4(2)] makes clear that determining what is in a person's best interests requires a consideration of all relevant circumstances." 49

Best interests is thus explained by reference not to a positive concept of (say) welfare (or indeed wisdom), but by negative reference to what a best interests determination is not based on: not "merely on a person's age, appearance, or unjustified assumptions about what might be in a person's best interests based on the person's condition or behaviour", 50 not "any unjustified and prejudicial assumptions". ${ }^{51}$ Equally, it is not a standard that is established by deciding as the person herself would: "Best interests is not a test of 'substituted judgment' (what the person would have wanted), but rather it requires a determination to be made by applying an objective test as to what would be in the person's best interests." 52

The explanatory notes describe the MCA as "offering further guidance" 53 on best interests to that found at common law. But the positive steps explained in section 4 are represented as suggested here; by reference to negative counterpoints. ${ }^{54}$ The guidance becomes so broad and contingent

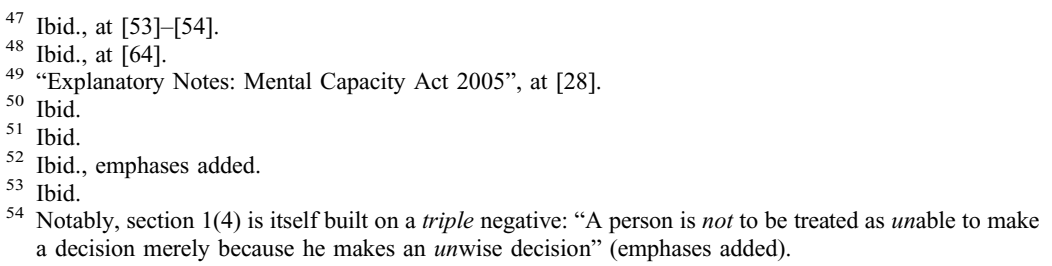


that it could not be much wider open, apparently reflecting the intention (rather than an accident) of statutory drafting.

It might therefore be hoped that reported cases provide a clearer exposition on best interests; or at least some positive indications of what best interests means, and how the values that guide a decision should be identified and applied. This is especially so given both that the statute "builds on the common law" 55 and that well over a decade's worth of authoritative interpretations of the Act have accumulated. There is, however, at once a wide-reaching body of jurisprudence, and a position wherein precedent is expressly provided as having no significant value. In the Court of Appeal case of $R B v$ Brighton and Hove City Council, ${ }^{56}$ Jackson L.J., with whom Arden and Fulford L.J.J. agree, reflects on the lack of application of precedent and the nature of statutory construction in mental capacity law:

The cases which arise for decision under Part 1 of the MCA ... tend to be acutely difficult, not admitting of any obviously right answer. The task of the court is to apply the statutory provisions, paying close heed to the language of the statute. Nevertheless, as judges tread their way through this treacherous terrain, it is helpful to look sideways and see how the courts have applied those statutory provisions to other factual scenarios. This has nothing to do with either the doctrine of precedent or the principles of statutory interpretation. The purpose is simply to see how other judicial decisions have exposed the issues or attempted to reconcile the irreconcilable. ${ }^{57}$

His Lordship thus refers to previous cases only for the purpose suggested above, whilst indicating that the "relevant principles are all to be found set out with clarity in the MCA". ${ }^{58}$ This may be true, but we might question the clarity on how the principles should be interpreted and applied. The explanatory notes themselves indicate section 4's indeterminacy and incompleteness: "All the relevant circumstances, including [and thus not limited to] the factors mentioned in the section must be considered [and thus appropriately identified], but none carries any more weight or priority than another. ... The factors in this section do not provide a definition of best interests and are not exhaustive." 59

The resultant position is that decision-makers must exercise their own judgment in identifying each matter that is relevant, according weight to it and weighing it up against all other relevant factors. The law by design gives limited guidance on how this should work. And the logic of this is embraced in $R B$, thereby disregarding concerns about apparent conflicts

55 "Explanatory Notes: Mental Capacity Act 2005", at [28].

${ }^{56}$ [2014] EWCA Civ 561, [2014] C.N. 854.

57 Ibid., at [40], emphasis added.

58 Ibid., at [61], emphasis added. The discussion of precedent forms a response to Hedley J.'s comments about conflicting judicial reasoning across five potentially relevant cases: see $A$ Local Authority $v H$ [2012] EWHC 49 (COP), [2012] 1 F.C.R. 590, at [18]-[19].

59 "Explanatory Notes: Mental Capacity Act 2005", at [28], emphases added. Judges have reaffirmed this point: e.g. Re M (Statutory Will) [2009] EWHC 2525 (Fam), [2011] 1 W.L.R. 344, at [32] (Munby J.). 
between reasoning in different judgments: ${ }^{60}$ the limited utility of the case law is acknowledged as a necessary consequence of the highly fact- and person-sensitive nature of mental capacity law. As Lady Hale states in Aintree v James: "The courts have been most reluctant to lay down general principles which might guide the decisions. Every patient, every case, is different and must be decided on its own facts." 61

Overall, the law therefore holds that if a person has capacity, she determines what may or may not happen. If she lacks capacity, ${ }^{62}$ a decision is not made by reference to what she would choose (although that may be relevant) but by reference to best interests: an undefined, non-exhaustively represented standard that operates without the bounds of customary approaches to statutory construction and common law precedent. English mental capacity law requires that we provide a necessarily distinct procedural frame to decision-making by a person on her own behalf, as contrasted with decision-making for $\mathrm{P}$; it also rests on an assumption that the forensic substance within the decision by a person on her own behalf should differ from the decision for P. Despite the best interests standard not being fully defined or unwise decisions being written out of it, to use Baroness Hale's language in Aintree, a person who has capacity can act against, or in a way that is inconsistent with, her own best interests.

Thus, albeit latently, best interests evaluations bear on understandings of capacitous decision-making. Equally, and also latently, unwise decisions come to be reflected against best interests determinations. In both cases they serve as substantive, further negative reference points, driving a conceptual wedge between the decisions by and decisions for persons. This conceptual separability may appear clear and logical. However, both formally and ethically, the law's respective rules for capacitous and incapacitous persons belie a point of complexity, uncertainty and practical and philosophical disagreement: best interests does not provide a stable, unequivocal or uncontestably meaningful point of reference. ${ }^{63}$ There is accordingly greater depth to explore in judicial contrapositions of autonomy (and unwise/subjective) against best interests (and wise/objective). This can be understood by examining judicial reasoning on freedoms to make unwise decisions and judges' problematisation of making unwise decisions on behalf of a person who lacks capacity.

60 As per the text quoted to note 57 , above.

61 [2013] UKSC 67, [2014] A.C. 591, at [36]. See also Sir Mark Hedley, The Modern Judge: Power, Responsibility and Society's Expectations (Bristol 2016).

62 And has no binding advance decision: MCA, ss. 24-26.

63 See also S. Holm and A. Edgar, "Best Interest: A Philosophical Critique" (2008) 16 Health Care Analysis 197; C. Kong et al., "An Aide Memoire for a Balancing Act? Critiquing the "Balance Sheet" Approach to Best Interests Decision-making” (2020) Med.L.R. 753. 
B. Unwise Decisions, the Place of $P$ and of D, and the Grounding of Best Interests

The radical variety of CoP cases, the extensive reach of principles enunciated in judgments (through "looking sideways") and the phenomena of vagueness and non-exhaustiveness embedded within the best interests standard, mean it becomes possible to:

- Represent, through judges' own reasoning, quite distinct substantive characterisations of unwise decisions and best interests;

- Distinguish judicial evaluations of the (de)merits of unwise decisions; and

- Contrast reasoning in relation to their prescribed course of action on the back of "unwise" reasoning.

We will explain each of these points in turn, developing a finer-grained representation that will then permit a critique of tensions between sections 1 (4) and 1(5) in Section IV of this paper.

Two points of caution from judicial dicta are helpful in guiding that consideration of judges' approaches to unwise decisions and best interests. The first emerges with the potential to conflate an unwise decision and a lack of capacity properly to weigh and use information. District Judge Jillian Bell, for example, criticised an expert witness in a case concerning a person's decision-making given his eating disorder for failing to "consider whether any of [the applicant's] reported actions were unwise decisions rather than indications of lack of capacity". ${ }^{64}$ Although in principle a clear separation here might be desirable, the apparent unwisdom of a decision can and does feature in evaluations of capacity. ${ }^{65}$

The second point of caution is articulated by Baker J., specifically against inappropriate importation of the "protection imperative" that explicitly frames child cases: 66

[I]n cases of vulnerable adults, there is a risk that all professionals involved with treating and helping that person - including, of course, a judge in the Court of Protection - may feel drawn towards an outcome that is more protective of the adult and thus, in certain circumstances, fail to carry out an assessment of capacity that is detached and objective. ${ }^{67}$

These points underscore the complexities of decision-making contexts where value judgments differ. They simultaneously challenge the idea

${ }^{64}$ FX v A Local Authority [2017] EWCOP 36.

${ }^{65}$ E.g. Cohen J.'s decision in Royal Borough of Greenwich v CDM [2018] EWCOP 15, especially at [52].

${ }^{66}$ See Oldham Metropolitan Borough Council v GW [2007] EWHC 136 (Fam), [2007] 2 F.L.R. 597, at [97].

${ }^{67}$ PH v A Local Authority [2011] EWHC 1704 (Fam), at [16]. Cf. also Heart of England NHS Foundation Trust v JB [2014] EWHC 342 (COP), [2014] C.N. 279, at [7] (Jackson J.): "The temptation to base a judgment of a person's capacity upon whether they seem to have made a good or bad decision, and in particular whether they have accepted or rejected medical advice, is absolutely to be avoided. That would be to put the cart before the horse or, expressed another way, to allow the tail of welfare to wag the dog of capacity." 
that clear, distinctive and - most importantly - theoretically and practically relevant contrasts can be made between constitutive components of (in)capacity determinations and best interests evaluations: the rules governing each may be clearly demarcated; the practical boundaries between them may not.

Nevertheless, perhaps the strongest explication of this apparently crucial contrast is found in $\operatorname{Re} P,{ }^{68}$ a case regarding P's will and the powers of his court-appointed deputy. Having conceptualised the contours of best interests by reference to materials including the MCA's explanatory notes, the Law Commission's Report on Mental Incapacity, ${ }^{69}$ the MCA Code of Practice $^{70}$ and various points of statute and jurisprudence, Lewison J. provides a canonical statement on unwise decisions:

[A]lthough the fact that $\mathrm{P}$ makes an unwise decision does not on its own give rise to any inference of incapacity (section 1(4)), once the decision making power shifts to a third party (whether carer, deputy or the court) I cannot see that it would be a proper exercise for a third party decision maker consciously to make an unwise decision merely because $\mathrm{P}$ would have done so. A consciously unwise decision will rarely if ever be made in P's best interests. $^{71}$

Lush J., former Senior Judge in the CoP, has approvingly cited these dicta, whose impetus directly reflects representations that he made leading up to the enactment of the MCA. ${ }^{72}$ Lush J.'s primary concerns related to property and affairs cases, where he has expanded on the shape and rationale for the basis of decision-making for persons who lack capacity. In Re Buckley, ${ }^{73}$ on the matter of investments made under a lasting power of attorney, his approach to D's and P's subjectivity differs from the prevalent rationale presented above in the parliamentary debates:

There are two common misconceptions when it comes to investments. The first is that attorneys acting under an LPA can do whatever they like with the donors' funds. And the second is that attorneys can do whatever the donors could - or would - have done personally, if they had the capacity to manage their property and affairs. Managing your own money is one thing. Managing someone else's money is an entirely different matter. ${ }^{74}$

The judge notes that capacitous persons "are generally not accountable to anyone" and "are entitled to make unwise decisions" about their

\footnotetext{
${ }^{68} \operatorname{Re} P$ [2009] EWHC 163 (Ch), [2010] 2 W.L.R. 253.

69 Law Commission, Report on Mental Incapacity.

70 Department for Constitutional Affairs, Mental Capacity Act 2005 - Code of Practice (London 2007).

${ }^{71} \operatorname{Re} P$ [2009] EWHC $163(\mathrm{Ch})$, at [42], emphasis added.

72 See Lord Christopher's speech, reflecting on a submission that Lush J., as Master of the Court of Protection, made to the Joint Committee that scrutinised the draft Mental Capacity Bill: HL Deb. vol. 668 col. 61 (10 January 2005). See also Letts, "Mental Capacity Act 2005".

73 [2013] EWHC 2965 (COP), [2013] C.N. 1460.

74 Ibid., at [20]-[21].
} 
money. ${ }^{75}$ When, however, another party is making the decision, Lush J. holds that the situation differs: first, because of fiduciary duties towards $\mathrm{P}$; second, because the requirement to decide in P's best interests is analytically distinct and therefore calls for reasoning according to its own standards. ${ }^{76}$ This approach to unwise decisions might be thought limited just to property and affairs. ${ }^{77}$ However, while Lewison J.'s reasoning has been predominantly cited in such cases, it has been referred to approvingly in health and welfare decisions as judges have "looked sideways" across the MCA's diversity of practical application. ${ }^{78}$

Nevertheless, challenges to the idea of a sharp distinction between unwise/capacitous and wise/best interests becomes apparent through reasoning such as in Briggs $v$ Briggs. ${ }^{79}$ Charles J. holds in a section of his judgment entitled "background law and principles":

[T] he law provides that patients who have capacity to make decisions about their medical treatment, and so who are in a position to exercise their autonomy or right of self-determination in respect of their treatment:

i) can choose to have or not to have the medical treatment that is on offer to them,

ii) that choice determines the lawfulness of the treatment, and so

iii) if those patients agree to have it the treatment is lawful, but

iv) if they refuse to have it the treatment is unlawful and cannot be given lawfully however strongly the treating doctors or others may disagree with that patient's choice.

Their determinative choice represents their conclusion on what promotes their own best interests. ${ }^{80}$

Charles J. distinguishes factors that feature in decision-making for capacitous and incapacitous persons, expressing how it is not the case that "a conclusion on what the relevant patient would have wanted and done if of full capacity is determinative of his best interests having regard to all relevant circumstances". ${ }^{81}$ Nevertheless, his characterisation of decision-making for capacitous persons pushes it into the same conceptual arena as best interests judgments that just happen to be made by a third party: by implication, unwise decisions are just about P's own values that others might not agree with. The practical distinction within this framing is more about

75 Ibid., at [22].

76 Ibid., at [23]-[26]. See also Re RG [2015] EWCOP 66, [2015] C.O.P.L.R. 794, especially at [38]-[39]

77 Cf. Mary Donnelly, "Determining Best Interests Under the Mental Capacity Act 2005" (2011) 19 Med. L.R. 304.

78 See Re M (Adult Patient) (Minimally Conscious State: Withdrawal of Treatment) [2011] EWHC 2443 (Fam), [2012] 1 W.L.R. 1653, at [81] (Baker J.); NHS Trust v L [2012] EWHC 4313 (Fam), at [118][119] (Moylan J.)

79 Briggs v Briggs [2016] EWCOP 53, [2017] 4 W.L.R. 37.

${ }^{80}$ Ibid., at [10], emphasis added.

${ }^{81}$ Ibid., at [22]. 
whose or which values better determine a person's interests, rather than the process either being or not being made on the best interests standard. ${ }^{82}$

Although this apparently cuts against Lady Hale's dicta cited above, the juridical background to Charles J.'s deliberations is the highly P-centric decision in Aintree $v$ James and its broad approach to understanding welfare. ${ }^{83}$ In a passage to which many $\mathrm{CoP}$ judges refer, Lady Hale holds:

[I]n considering the best interests of this particular patient at this particular time, decision-makers must look at his welfare in the widest sense, not just medical but social and psychological; they must consider the nature of the medical treatment in question, what it involves and its prospects of success; they must consider what the outcome of that treatment for the patient is likely to be; they must try and put themselves in the place of the individual patient and ask what his attitude to the treatment is or would be likely to be; and they must consult others who are looking after him or interested in his welfare, in particular for their view of what his attitude would be. ${ }^{84}$

Though Lady Hale distinguishes a person's own capacitous decision and D's best interests decision, this reasoning (including in cases such as Briggs) has promoted according much greater weight to P's particular values and to assuring a broad understanding of welfare. Aintree has, in theory, reduced the conceptual wedge which has traditionally delineated subjective wishes and feelings as opposed to objective best interests (i.e. decisions by as opposed to for a person) in many pre- and early-MCA cases. In their post-legislative scrutiny of the MCA, the House of Lords Select Committee Report interpreted Aintree as "placing greater emphasis on the role of $\mathrm{P}$ in the best interests process while simultaneously diminishing the importance of objective criteria". ${ }^{85}$ Hayden J. also recently held in the CoP:

There is now a raft of case law ... which illustrate the efforts the Court of Protection will got to in order to identify what the likely wishes of P would be .... Whilst the identified wishes of $\mathrm{P}$ will not in and of themselves be determinative, they will always be given substantial weight and are highly likely to be reflected in the order or declaration the Court makes. ${ }^{86}$

Developments in case law since Aintree seem to suggest initially an apparent shift towards greater determinative weight being given to P's values in a best interests decision, especially compared to pre- and early-MCA cases. That said, the strength of the movement in this direction might be tracked differently within the history of (mental) health and welfare law as contrasted with property and affairs. Furthermore, even with recognition of general trends, such developments have not made notions of objective

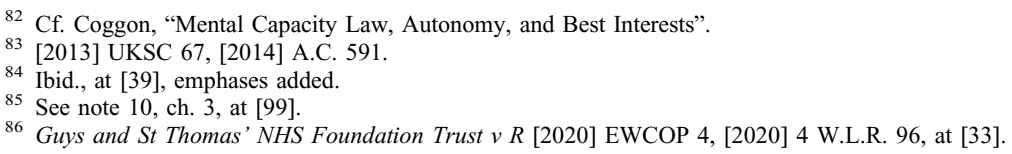


assessment disappear altogether in best interests decision-making. This is seen clearly through rejections of unwise (or irrational, unreasonable, eccentric, etc.) subjective decision-making in favour of various placeholders for more idealised, purportedly objective values in recent cases, as exemplified in the appeal to a hypothetically conceived person with capacity (who never existed) in University Hospitals Bristol NHS Foundation Trust $v$ ED, or reference to a "window of lucidity" in A Clinical Commissioning Group v AF \& Ors. ${ }^{87}$ Indeed, we need to probe more deeply what appears to be motivating this overly simplistic dichotomy of subjective and objective considerations. In order to do so, the prism of unwise decisions permits a closer scrutiny of questions of non-P-centricity, as discussed in Section IV and enables us to challenge the view that the principled conflicts between sections 1(4) and 1(5) are reducible to separable autonomypromoting and welfare-promoting components respectively. ${ }^{88}$

\section{Conceptual Assumptions and Theoretical Accounts of Practical WisDOM In JUdiCIAL RATIONALISATIONS}

\section{A. Digging Deeper: Unwise Decisions and Their Judicial Rationalisation}

Mental capacity jurisprudence presents ranging implicit and explicit characterisations of unwise decisions. Improved grasp of these helps explain the relative weight that is given to P's values, beliefs, wishes and feelings in best interests determinations, and the overall links and tensions in judicial approaches to the principles in sections 1(4) and 1(5). As we have argued, variation in judges' reasoning is unsurprising. An initial liberal framing would aim with section 1 (4) to protect a thin conception of autonomy, as consistent with views expressed in the parliamentary debates: the provision then might be said to shun rather than invite substantive analysis of the meaning of (un)wisdom. However, scrutiny of judicial rationalisation around unwise decisions reveals a conceptual grounding in substantive criteria associated with practical reasoning and decisional outcomes. This in turn indicates that tensions within the law go beyond mere case context-specificity and legislative indeterminacy. There are different ways in which P's values - even ones that she demonstrably espouses - can be treated as inferior to other values that might motivate a putatively "better" decision. Analysis of the case law suggests three particular bases for this:

(1) The decision itself can be placed within its own bounded rationality that imposes its own wisdoms on what should be done.

(2) The outcome of the decision is offensive to a concept of welfare whose rigour is sufficiently compelling that this rules out the decision itself as wrong.

${ }^{87}$ [2020] EWCOP 16.

88 Cf. e.g. Lush, "The Mental Capacity Act and the New Court of Protection". 
(3) The outcome of the decision is offensive to a concept of welfare whose rigour is sufficiently strong that it should be treated as having strong presumptive weight. The burden of breaking its presumptive weight requires, for example, formalities to be followed, or a clear, internally-coherent alignment of P's values, wishes, beliefs and feelings that offend the concept of welfare in this sense.

These three share a common justificatory grounding which treats P's values as essentially wrong because they are "objectively" problematic. They appeal to some higher-order truth about P's interests quite regardless of her - or any other person's - wishes, beliefs, values and feelings. We examine each in turn.

\section{The nature of the decision imposes a particular rationality}

The MCA builds on rationales for adopting a functional, decision-specific approach to understanding capacity, as contrasted with a status-based or outcome-based approach. ${ }^{89}$ Outcome-based approaches in practice can be seen to impact judgments about the wisdom of a decision (see Sections IV(B) and (C), below). By contrast, the functional approach purportedly advances a value-neutral stance which avoids basing capacity assessments on the decision's substance or outcome. Yet even here it is possible to see instances of best interests decisions where the function of reasoning itself is taken as unwise not just because of where it leads, but because of its being considered inappropriate.

The most straightforward examples are cases such as $R e P$, discussed above, where financial decisions are made for P. Lewison J.'s dicta in that case indicate that financial decisions must be made according to an economic rationality, even where $\mathrm{P}$ would not have made such decisions according to such reasoning. As already discussed, former Senior Judge Lush identifies two legal foundations for this: first, D owes P a fiduciary duty; second, perhaps with some circularity, D has to serve P's best interests. The circularity is suggested because financial decisions that are judged to be poor on economic grounds are taken as necessarily poor decisions in terms of what would serve P's interests: economic rationality is taken as analytically the better frame for best interests (i.e. better than vindicating P's wishes).

\section{The decision itself is unwise for its outcomes for P's welfare 1}

Despite the position that capacity is not checked by reference to outcomes, (probable) outcomes nonetheless have an impact on decisions about the "wisdom" of a decision. This applies in cases where capacity itself is

89 Law Commission, Report on Mental Incapacity. 
under issue (albeit that, as seen above, judges warn against conflating unwise decisions with an inability to use and weigh information) and in cases where P's wishes, beliefs, values and feelings are well known but not allowed to guide a best interests determination. Cases about children decided under the MCA are clear examples, such as An NHS Foundation Hospital $v P,{ }^{90}$ which was heard by Baker J. P was refusing an intervention following a paracetamol overdose. Because of the rules in capacity law concerning children of 16 and 17 - namely meaning that the capacity, and consequent right, to consent is not mirrored precisely by a right to refuse $^{91}$ - the judge could find a lack of capacity to refuse based on a hard commitment to what would serve P's welfare.

Importantly, the "welfare" component in best interests decisions concerning children is broader than the standard that is applied to adults. ${ }^{92}$ Cases such as $P$ nonetheless bring analytical value to discussions of unwise decisions because they circumscribe decisions and promote particular sorts of determination. Such reasoning has limited best interests decisions for adults, for example in cases regarding childbirth and reproduction, such as NHS Trust $v J^{93}$ and The Mental Health Trust \& Ors $v$ DD \& Anor. ${ }^{94}$ Though welfare is not explicitly appealed to, it nonetheless serves as the backdrop which legitimates overruling P's purportedly unwise wishes, which were clearly known in both cases. NHS Trust $v$ JP concerned how JP's baby would be delivered. Based on the least worst option, Williams J. concludes that a planned caesarean would be in JP's best interests, despite her consistently expressing the desire for a vaginal birth. The judge implicitly draws on the unwisdom of choosing a birth plan that invites physical and emotional pain. ${ }^{95}$ Cobb J. in Mental Health Trust $v$ $D D$ also uses an outcome-based determination of best interests to authorise sterilisation of $\mathrm{DD}$, overturning her repeated resistance to contraceptive treatment and third-party interventions. DD was at high risk of lifethreatening complications if she fell pregnant again (she had six children in a short span of time). On that basis, Cobb J. authorised forcible sterilisation in her best interests, as this would ultimately bring about the "normal life", free from third-party intrusion, that DD so desired. ${ }^{96}$

90 [2014] EWHC 1650 (Fam), [2014] Fam. Law 1249.

91 Cf. S. Gilmore and J. Herring, “'No' Is the Hardest Word: Consent and Children's Autonomy” (2011) 12 C.F.L.Q. 3

92 S. Choudhry, "Best Interests in the MCA 2005 - What can Healthcare Law Learn from Family Law?" (2008) 16 Health Care Analysis 240.

93 [2019] EWCOP 23, [2019] C.O.P.L.R. 298.

94 [2015] EWCOP 4.

95 [2019] EWCOP 23, at [42]. JP had eventually managed a natural birth before the judgment was finalised, leading Williams J. to reflect at [48] that: "The capacity for individuals to confound judges' assessments is a reminder (to me at least) of the gap between probability and actuality."

96 At [113]. This controversial case also involves numerous troubling assumptions around gender and learning disability: see C. Kong, "Constructing Female Sexual and Reproductive Agency in Mental Capacity Law" (2019) 66 International Journal of Law and Psychiatry 101488. 
3. The decision is unwise for its outcomes for P's welfare 2

The jurisprudence demonstrates alternative framings wherein "objective" values can steer a best interests determination even if this contradicts what evidently would be P's values. We can exemplify this first with Baker J.'s decision in Re M. ${ }^{97}$ This is the first case providing a determination on the lawfulness of continued treatment (nutrition and hydration) of a person in a minimally conscious state. ${ }^{98}$ Evidence was accepted that Mrs. M had expressed a clear view that her preferred course of action would be non-treatment in the circumstances that had materialised. Nevertheless, Baker J. holds that treatment should be continued in her best interests, suggesting that for her values to determine the situation, she would need an applicable advance decision under sections 24-26 MCA. This is particularly demanding given that she had suffered the brain damage four years before the MCA's formal requirements concerning advance decisions came into force. It shows that while the court may be bound to set aside the "objective" value of continued life, this will not be as (what might be framed as) an "unwise" best interests decision.

Avoiding "unwise" outcomes is also apparently possible where P's own reasoning and values seem internally/mutually inconsistent. Here the default decision becomes the "wise" one. For example, A NHS Trust v Dr. $A,{ }^{99}$ again heard by Baker J., concerned a man who was refusing food as a hunger strike to avoid deportation. Baker J. clearly views this as unwise, stating: "In this context, where the consequences of a decision will be fatal for Dr. A, the court must in my view be particularly careful not to treat him as incapable of making a decision merely because the decision is extremely unwise."100

Dr. A's decision-making was hampered by contradictions in his own reasoning and beliefs: sometimes saying he wanted to die; ${ }^{101}$ sometimes holding apparently inconsistent wishes on this; ${ }^{102}$ sometimes not wanting to die but recognising it as an acceptable and necessary consequence; ${ }^{103}$ and sometimes expressing happiness that he had not been allowed to die. ${ }^{104}$ The case demonstrates how a "wise" default (namely, a life-saving intervention) may both underpin and circumscribe the final decision on best

${ }^{97}$ Re $M$ [2011] EWHC 2443 (Fam). This case cited and discussed with approval the reasoning in Re P [2009] EWHC 163 (Ch).

98 A. Mullock, "Deciding the Fate of a Minimally Conscious Patient: An Unsatisfactory Balancing Act? $W$ $v M$ and Others [2011] EWHC 2443 (Fam)" (2012) 20 Med.L.R. 460.

99 [2013] EWHC 2442 (COP), [2014] 2 W.L.R. 607. Notably, Dr. A was also being treated under the Mental Health Act 1983, s. 3.

100 Ibid., at [34].

101 Ibid., at [10].

102 Ibid., at [15].

103 Ibid., at [16]

104 Ibid., at [18]. 
interests, in a way that could not (in principle) apply where a decision is being made by a capacitous person.

\section{B. The Underlying Normative Concept of Wisdom}

Superficially, it is easy to assume that the disparate meaning and normative function of unwise decisions in judicial rationalisations indicates incoherent reasoning and conceptual ambiguities, in turn suggesting a problematic justificatory grounding for certain capacity assessments and best interests decisions. However, the unclear normativity of "wisdom" might be attributable to a key but subtle tension between the legislative intent of the phrasing as discussed in Section II and the normative ideal of wisdom that prevails in ordinary and theoretical conceptualisations. The parliamentary debates foreground how the MCA's principled basis was designed to make personal decision-making as person-centric as possible; placing the individual's wishes, feelings, beliefs and values at the forefront so that regardless of circumstance, disability or impairment, she is on an equal footing with everyone else.

The normative idea of wisdom, by contrast, brings explanatory value to the more demanding justificatory criteria around reasoning and decisional outcomes in judicial rationalisations, creating a conceptual wedge between (what is viewed as) objectively "best" or "wise" decisions and the person's subjective wishes. Prevalent commonsense notions of wisdom often appeal to a substantively rich understanding of decision-making with roots originating from a long philosophical tradition. ${ }^{105}$ Recent wisdom studies combine philosophical and lay intuitions to elucidate the normative cognitive, affective and motivational features of wisdom, including the accumulation of experience, understanding, reflection, problem-solving capacities and the motivation to make good choices in light of complex human problems. ${ }^{106}$ Through folk theories and experimental psychology, these studies often treat wisdom as an "expert skill" that requires faculties of character and intellect, ${ }^{107}$ whilst its substantive characterisations emphasise balancing different interpersonal and extrapersonal interests, and adapting to new and existing environments. ${ }^{108}$ As an expression of certain values and a particular ethical orientation towards life, 109 its demanding characteristics include "deep and broad insight into self, others, and the world", "complex

105 N.M. Weststrate, S. Bluck and J. Glück, "Wisdom of the Crowd: Exploring People's Conceptions of Wisdom" in R.J. Sternberg and J. Glück (eds.), The Cambridge Handbook of Wisdom (Cambridge 2019), 97-121.

106 V. Tiberius and J. Swartwood, "Wisdom Revisited: A Case Study in Normative Theorizing" (2011) 14 Philosophical Explorations 283.

107 J. Swartwood, "Wisdom as an Expert Skill" (2013) 16 Ethical Theory and Moral Practice 511.

108 Weststrate, Bluck and Glück, "Wisdom of the Crowd: Exploring People's Conceptions of Wisdom"; R. J. Sternberg, "Foolishness" in R. Sternberg and J. Jordan (eds.), A Handbook of Wisdom: Psychological Perspectives (Cambridge 2005), 344-46.

109 Swartwood, "Wisdom as an Expert Skill". 
emotion regulation" and "a motivational orientation that is transcending self-interest and is invested in the well-being of others and the world". ${ }^{110}$ As such, wisdom is thought to embody traits in action as well as the ability to identify its instantiation in a manner that echoes aesthetic judgment, thus potentially revealing a hierarchy of wisdom, ranging from common, everyday pragmatic action, to that which is uncommon and transcendent. ${ }^{111}$

It is not immediately clear how these substantive characterisations of wisdom track the normative presuppositions within judicial rationalisations around the wisdom/unwisdom of reasoning or decisional outcomes. But closer examination of the philosophical origin of wisdom studies in Aristotle proves more illuminating, highlighting core deliberative features of practical wisdom which encompass both the logic of a particular rationality and the outcome of decisions. For Aristotle, practical wisdom is the mark of the individual who "deliberate[s] well about what is good and expedient for himself, not in some particular respect, e.g. about what sorts of thing conduce to health or to strength, but about what sorts of things conduce to the good life in general". ${ }^{112}$

This person of practical wisdom is "capable of aiming in accordance with calculation at the best for man of things attainable by action" and is not "concerned with universals only - it must also recognize particulars". ${ }^{113}$ Deliberative manifestations of practical wisdom therefore involve both the ability to determine means to an end (or basic instrumental rationality) "the attainment of particular formed objectives" - as well as the ability to specify constituents of an end, thereby answering "questions of general policy - what specific objectives to form". ${ }^{114}$ Or to use the broad categories of judicial rationalisation, deliberative features of Aristotelian wisdom are bound up with both the specific outcome of decisions as well as the rational logic as required by the decision itself.

In this fairly expansive definition, Aristotle addresses the type of deliberation that involves considering the overarching human good, reflecting on the good life as a whole, and the more particularistic kind that instantiates the good as appropriate to the circumstances. For example, having a generalised picture of the good in life and the role of generosity in life as a whole helps determine when it is appropriate to give and to whom. Without a vision of what the point is of one's actions, one ends up like a "sturdy body stumbling for want of sight". ${ }^{115}$ Skills of perception enable

${ }^{110}$ W.S. Brown, "Discussion: Seven Pillars of the House of Wisdom" in Sternberg and Jordan, $A$ Handbook of Wisdom, 18.

111 Ibid.

112 Aristotle, Nicomachean Ethics, trans. W.D. Ross, in The Complete Works of Aristotle, vol. 2 (Princeton 1984), NE 1140a43.

113 Ibid., at $1141 \mathrm{~b} 9$.

114 D. Wiggins, "Deliberation and Practical Reason" in A.O. Rorty (ed.), Essays on Aristotle's Ethics (Berkeley 1980), 37.

115 R. Sorabji, 'Aristotle on the Role of Intellect in Virtue' in Rorty, Essays on Aristotle's Ethics, 206. 
one to perceive and identify what is important, relevant and when. ${ }^{116}$ These perceptual skills are inculcated through the habituation of character so that one learns to desire and be motivated towards what is possible for a human life in its distinctive functioning. Equally, practical wisdom demands developing the intellectual virtues associated with the ability to reason and reflect in ways that recognise the constituent goods that promote what is possible and desirable in human life.

Aristotle's account of practical wisdom is therefore rooted in a substantive but indeterminate vision of appropriate goods and ends for human beings, and how one should deliberate towards these. Deliberative features of wisdom are not value-neutral, wholly subjective or premised on an impartial stance towards values, nor are they reducible to appetite, perceptual or cognitive traits. Rather, emotional, perceptual and intellectual skills work in concert to promote a certain vision of the good human life and the goods that constitute that goodness-though these nonetheless remain fairly underspecified. ${ }^{117}$ Unlike contemporary wisdom studies, Aristotle lacks a concrete characterisation of what the human good looks like. But this very indeterminacy represents a key deliberative feature of practical wisdom. What constitutes the good by nature lacks any fixity: what is appropriate will depend on the suitability of the proposed course of action as determined by the context-specific circumstances. ${ }^{118}$ The impossibility of adopting or appealing to a clear rule to suit every case makes situational appreciation a constitutive feature of what it means to be practically wise; deliberation will be responsive and particularistic. ${ }^{119}$

Through an Aristotelian lens, the justificatory grounding of judicial appeals to wisdom/unwisdom need not appear inconsistent or arbitrary, but rather may be said to track a powerful intuition that practical wisdom manifests itself through certain deliberative features, such as coherent reasoning that is responsive to context, circumstance and actively promotes certain outcomes or goods in one's decision-making. Aristotle's account thus has descriptive value in its elucidation of the common, if relatively inchoate, normative grounding for the conceptual wedge between a person's subjective choices and best interests decisions in judicial rationalisations. Much less than a groundless espousal of random or arbitrary judgments, such rationalisations can be seen to draw upon a more substantively rich understanding of how decision-making could be approached, whether by a person on her own behalf or by (say) a judge for P.

116 We set aside the substantial debate about the extent to which wisdom involves intellectual as opposed to perceptual skills within Aristotle.

117 Aristotle ultimately endorses the political and philosophic life, but this has not prevented interpreters to read a more expansive definition of the good life in Aristotle's philosophy.

118 See M.C. Nussbaum, The Fragility of Goodness: Luck and Ethics in Greek Tragedy and Philosophy (Cambridge 1986).

119 Ibid., at 305 . 
Whilst this conceptualisation of wisdom has explanatory potential in its illumination of how the substantive ideal chafes against legislative intent, it also raises difficult questions around the justificatory function of such standards within the MCA. The Aristotelian emphasis on deliberative flexibility and indeterminate practical goods may suggest a perspective that is sympathetic to the liberal commitment to value pluralism, individual expression and incommensurability. ${ }^{120}$ However, even within Aristotle's broad constraints, motivational, perceptual and intellectual virtues are highly demanding prerequisites to wisdom: individuals must desire what is good and appropriate, possess the ability to perceive and identify relevant features of what is good in the circumstances and accumulate sufficient experience to eventually judge and reflect on their lives as a whole. Not only would practical wisdom constitute an exacting bar for most individuals to attain-possibly making it even more challenging for those with cognitive impairments-but its prerequisites constitute a (potentially) controversial value basis on which to judge the choices of others; an outcome that would counter the liberal commitments within legislative intent, as explained above.

\section{Irreconcilable Tensions?}

Bringing together the legislative debates and more normative accounts of wisdom lays bare two interpretive but conflicting pathways to interpreting the operation of principles in sections 1(4) and 1(5) in relation to specific decisions. The first promotes a thin liberal interpretation of unwise that places P's subjective wishes at its heart. The second, more substantive approach implicitly draws on more philosophical accounts and common folk intuitions and subjects a person's wishes, and indeed, the reasoning and content of decisions, to a higher level of scrutiny. Judicial rationalisations confirm that a consistently understood legal definition and usage of unwise decisions remains elusive, similar to that of best interests. Conceptual and policy interpretations of unwise/wise help pinpoint some reasons behind this inconsistency. Appeals to unwise decisions in section 1(4) adhere more closely to liberal commitments to subjective freedom, yet the typical markers of best interests in judicial interpretations of sections $1(5)$ and 4 - decisions that are rational, practicable, etc. - involve cognate concepts of a substantive vision of wisdom. Whilst there is acknowledgement that capacitous persons should be allowed to make unwise decisions, judicial rationalisations suggest discomfort with adopting a thin criterion in best interests and abandoning a more normative vision of wise deliberation in making decisions for P. This normative vision guides not just how P's

${ }^{120}$ Ibid. and Wiggins, "Deliberation and Practical Reason". For alternative readings, see C.D.C. Reeve, Practices of Reason: Aristotle's Nicomachean Ethics (Oxford 1992); T.H. Irwin, Aristotle's First Principles (Oxford 1989); R. Kraut, Aristotle on the Human Good (Princeton 1991). 
subjective wishes may be evaluated, but also potentially how judges themselves are to deliberate in determining best interests. ${ }^{121}$

The concept of wisdom/unwisdom is therefore characterised by inherent instability between the "thin" liberal interpretation and "thicker", more normative connotations. As such, the contested domain of unwise decisions represents a real test of commitment to the person's values, both in capacity assessment (does it protect expressions of individual personality or act as an alert of incapacity?) and best interests decision-making (should presumptive weight be accorded to P's "unwise" values or does it legitimate the meta-examination of such values in light of some human good?). Arguably, this highlights the need for a concrete legal definition of wisdom which preserves either legislative intent or idealised content in a consistent, general manner. If the former, the legislative genealogy of section 1(4) points to the protection of individual expression and eccentricity as a matter of exercising autonomy-a normative agenda aligned with the demand for exclusively person-centric decisions in Article 12 of the United Nations Convention on the Rights of Persons with Disabilities, which, at least in the Committee's General Comment, stresses the determinative weight of the person's subjective values, wishes and feelings, regardless of capacity. ${ }^{122}$

Yet, as shown above, divesting the normative connotations of wisdom has proven highly difficult in practice. The manner in which wisdom and its cognates function in judicial rationalisations gestures towards inchoate criteria of the types of thinking, reasoning, values that warrant certain moral standing, and in turn, the weight that should be accorded to P's views in best interests determinations. The counterintuitive usage of unwise in section 1(4) remains prone to ambiguity and appears too weak to offset the more pervasive, normatively-laden notions of wisdom that creep into judicial rationalisation. Although it is of limited reach in its detail or intended application, the presumptive value of wise decisions continues to invite implicitly the critical assessment of an individual's decisions, measuring her own value perspective both in capacity assessment and best interests decision-making, and indeed often leading to a conflation of the two. In contrast, preserving the more idealised grounding of wisdom provides some justificatory basis for precisely this type of

121 As Suzanne Doyle Guilloud has pointed out to us, different judicial perspectives and reasoning may be judged as including 'unwiseness' from the perspective of other judges: e.g. Guys and St Thomas $v R$ [2020] EWCOP 4, at [56], Hayden J. holds: "It is, I think, important to acknowledge, as others have done, that judges in the past may have strained to conclude that women, in these difficult circumstances, lacked decision making capacity in order, for the highest of motives, to protect the life or health of both the mother and her unborn child. To give the mother's articulated position this very limited interpretation would, on careful reflection, be sophistry, designed to enable me to protect the mother and her unborn child without confronting what I consider to be the true evidential picture."

122 CRPD Committee, "General Comment No. 1". Though we have serious reservations about the controversial General Comment interpretation of Article 12, the ethos of putting $\mathrm{P}$ at the centre of decisionmaking nonetheless lies at the heart of the CRPD. 
meta-examination of P's values in the best interests test; something that judicial rationalisations wish to retain. In theory, this would make explicit the values basis for certain best interest decisions, though at the expense of according absolute priority to P's own values and their idiosyncratic expression.

Whether one favours preserving legislative intent or the normative ideal, attempts to coalesce around a generalised, concrete legal definition of wisdom run contrary to its very meaning. Using the concept of wisdom to achieve judicial consistency would be an odd strategy; especially as wisdom's core normative feature involves skills to navigate context-specificity and indeterminacy as opposed to uniform rule application. Indeed, the best interests standard tracks such indeterminacy: section 1(5), as explicated in section 4 , outlines the legal obligation to make decisions in unique, unrepeatable circumstances; such indeterminacy is constitutive of the duties that are owed. Drawing on generalised, rule-driven terms runs counter to the requirements of wisdom, but also the very aims and obligations of the legislation.

Moreover, a generalised approach seems fundamentally problematic from the standpoint of judicial logic. From different angles, the conceptual instability of wisdom within the MCA presents a dilemma: if the liberal intent of "unwise" in section 1(4) likewise holds in the best interests standard, judges would need to prioritise P's subjective wishes and feelings and could not claim that best interests excludes unwise decisions. This suggests that the best interests standard is judged by the same, minimal criteria of section 1(4), where P's subjective choices are presumptively weighted regardless of capacity. But the danger is that this leaves a poorly anchored, subjectivist notion of best interests incapable of providing nuanced decisions in context-specific and often ethically-fraught circumstances. ${ }^{123}$ Achieving consistent judicial logic across the principles expounded in sections 1(4) and 1(5) is bought at the expense of the best interests standard itself. However, judicial rationalisations that draw on divergent notions of wisdom and its cognates in section 1(4) and in the detail of interpreting sections 1(5) and 4 may avoid the overly subjectivist slant to the best interests standard. This then represents an entrenched discretionary dimension to such judicial decisions, with dangers of inconsistency, unpredictability and, in some cases, the failure to promote P-centric judgments; indeed, as forewarned in Parliament, it risks D's subjective values being the determinative factor in decision-making.

Our analysis does not lead to a determination for or against either interpretation: it remains possible that best interests decisions that follow one or

${ }^{123}$ See C. Kong, "The Significance of Strong Evaluation and Narrativity in Supporting Capacity" in M. Donnelly, R. Harding and E. Taşcioğlu (eds.), Supporting Legal Capacity in Socio-legal Context (Hart forthcoming 2021). 
the other could be disputed and questioned on multiple grounds. But we have shown that the MCA, coupled with the idiosyncratic and sometimes contradictory appeal to unwise decisions in case law, invites the simultaneous consideration of and abstraction from P's values and wishes. It is tempting to condemn more substantive judicial rationalisations which appeal to wisdom and its cognates as legally baseless; as instances of judicial overreach and paternalism. However, this overlooks how appeals to higher-order reasons in deliberating best interests track powerful, more normative accounts around practical wisdom, highlighting the slightly counterintuitive nature of the liberal interpretation of unwise as propounded in the parliamentary debates. The widespread, intuitive appeal of such normative accounts cannot be so easily dismissed.

At a minimum, our analysis calls into question the suitability of providing for the principled aims of section 1(4) on the terms through which the subsection is formulated. Our argument shows that the MCA's principled bases compound rather than allow coherent resolution of the Act's inherent principled tensions. The MCA is intended to put the person to whom it applies at the centre of decisions. But its framing has the effect of further entangling and obscuring the impacts of "objective" versus "subjective" as proxies for less clearly stated principles to arrive at better - if not the best possible - decisions: it creates an unavoidably unstable foundation for differential accounts of the better determination by or for the person.

\section{CONCLUSION}

This article has shown how the principles in sections 1(4) and 1(5) cannot stand together as foundational precepts for the MCA's sound operation and its realisation of P-centric objectives. The tensions between them are irreconcilable and individually they fail to reconcile imperatives that arise both in relation to our understandings of capacitous decisions and of what values should inform best interests determinations. What initially strikes one as arbitrariness in judicial rationalisations is an inevitable consequence of such contrary imperatives within the legislation, operating within the context of prevalent assumptions around practical wisdom. Theorisations of wisdom bring powerful explanatory potential to how the law can and should operate, but also expose the flaws in a bald statutory provision that ties itself to unwisdom and which inevitably comes to operate too in conjunction with cognates such as irrationality and eccentricity. Paradoxically, the application of the MCA thereby leads to abstractions from specific decisions. In so doing, instead of promoting its very core principle - placing the person at the heart of consideration - it has the opposite effect: the principled distancing of the person from decisions that are intended to ensure she is at their centre. 